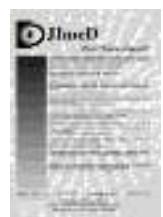

Jurnal Imejing Diagnostik (JImeD) 6 (2020) 23-27

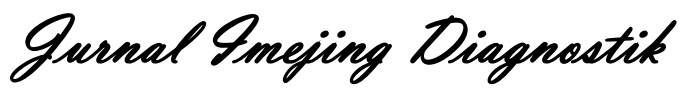

e-ISSN 2621-7457, p-ISSN 2356-301X

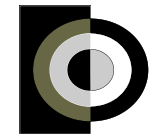

http://ejournal.poltekkes-

smg.ac.id/ojs/index.php/jimed/index

\title{
Penggunaan Variasi Filter pada Windowing Lung pada Pemeriksaan CT Scan Thorax
}

\author{
Sudiyono $^{1}$ Rini Indrati ${ }^{2}$ Muhammad Riefki Jadmika ${ }^{3}$ \\ ${ }^{1,2)}$ Jurusan Teknik Radiodiagnostik dan Radioterapi, Poltekkes Kemenkes Semarang, Indonesia \\ ${ }^{3}$ Dr. Sardjito Hospital, Yogyakarta, Indonesia \\ Corresponding author: Sudiyono \\ Email: dionsudiyono1967@gmail.com
}

Received: January $30^{\text {th }}$, 2020; Revised: January $31^{\text {th }}, 2020$; Accepted: January $31^{\text {th }}, 2020$

\begin{abstract}
Background: Filter is an image processing parameter applied to raw data used to determine the attenuation value of each pixel of CT Scan imaging, and it serves to minimize the occurrence of star patterned streak artifacts formed on the CT images. The use of typical Y-sharp or Smooth filters is common for the thoracic CT imaging in the clinic. Yet, the studies to compare which of the typical filters that provide a good imaging technique were clinically limited to find in practices. The purpose of this study is to know wheter there is a difference or not in the anatomical image resolved amongst the thoracic CT images when using the Y-Sharp and Smooth filters; and to determine which of the filter that produces the better image quality by comparison.

Methods: This is quantitative research with approached the pre-experimental design with the static-groups of comparison. Image data were taken from the raw data of the 10 patients who underwent CT Scan Thorax examinations. All the image data were reconstructed by means of using the Y-Sharp and Smooth filters. Assessment of the images were performed by 2 radiologists. The Cohen's Kappa was used for image evaluators agreement where the Wilcoxon Test was applied to test the hypotheses.

Results: The result of this study showed that there is a significant difference in anatomical organ visualization of the thoracic CT images between filter the Y-Sharp and Smooth filters with $p$-value 0.005. The use of Y-Sharp filter is better as it produces a high spatial image resolution.

Conclusions: The anatomical organs of the thoracic CT images are visually reproduced when the Y-sharp filter is employed. The comparison between the two different filter uses deems significance.
\end{abstract}

Keyword : Y-Sharp filter; Smooth filter; CT Scan Thorax

\section{Pendahuluan}

Pemeriksaan CT Scan Thorax biasanya dilakukan dalam dua variasi windowing yaitu window mediastinum dan window lung. Window mediastinum memberikan citra yang baik untuk melihat dinding dada, organ pada daerah mediastinum dan pleura. Sedang pada window lung memberikan citra untuk melihat jaringan paru termasuk area konsolidasi dan struktur vaskularisasi pulmoner (Seeram, 2016).

Pada pengaturan windowing lung agar mendapatkan citra yang lebih detail diperlukan pengaturan filter/rekonstruksi algoritma yang tepat.
Menurut Romans (2011) filter/rekonstruksi algoritma didefinisikan sebagai suatu metode matematika komputer rumit yang berfungsi untuk meminimalisasi terjadinya streak artefak berpola bintang yang terbentuk pada citra CT Scan. Merubah filter diartikan sebagai merubah cara memanipulasi raw data untuk merekonstruksi citra. Terdapat bermacam variasi filter yang disediakan oleh pabrikan tergantung pada bagian mana area obyek yang akan dipertajam atau diperhalus.

Pemilihan dari variasi rekonstruksi algoritma/filter menurut Boedeker (2004) berpengaruh pada spatial resolusi dan noise. Resolusi algoritma/filter yang tinggi (bone, sharp, 
very sharp) menghasilkan spatial frequency yang tinggi sehingga akan terbentuk citra dengan spatial resolusi yang baik tapi mempunyai tingkat noise yang tinggi pula. Sebaliknya algoritma yang lebih smooth/halus akan mereduksi high spatial frequency dan berakibat menurunnya noise dan spatial resolusi.

Penggunaan filter pada pemeriksaan CT Scan Thorax menurut Henwood (1999) biasanya dilakukan menggunakan jenis filter smooth untuk mengurangi noise citra karena efek dari beberapa obyek yang tebal seperti lengan, pacemaker ataupun dari obyek tubuh pasien yang lebih besar dari ukuran normal. Menurut Salito (2011) menjelaskan penggunaan filter jenis smooth sangat penting terutama digunakan untuk klinis seperti emphysema. Sedangkan menurut Zwirewich (1989), mendeskripsikan engunaan filter jenis sharp pada CT Scan Thorax bertujuan untuk memperlihatkan parenkim paru, struktur pembuluh darah kecil dan bronkhus paru dan pemeriksaan ini sering dikenal dengan istilah High Resolusi CT Scan. Bahkan penggunaan filter sharp direkomendasikan untuk pemeriksaan $C T$ Scan Thorax rutin.

Pemeriksaan CT Scan Thorax rutin sering dijumpai di Instalasi Radiologi RSUP Dr. Sardjito yang menggunakan modalitas CT Scan merk Philips Ingeunity 128 dan dibuat dalam dua kondisi windowing yaitu windowing mediastinum dan lung. Pengaturan parameter filter di modalitas CT Scan merk Philips Ingenuity 128 di instalasi radiologi RSUP DR. Sardjito Yogyakarta pada pemeriksaan CT Scan Thorax rutin dalam windowing mediastinum dan lung adalah filter jenis smooth. Namun dari pengamatan peneliti selama bulan Januari 2017 sampai dengan tahun 2018, dokter spesialis radiologi konsultan thorax di Instalasi Radiologi RSUP DR. Sardjito Yogyakarta sering meminta penambahan penggunaan parameter filter $Y$-Sharp pada windowing Lung dalam pemeriksaan CT Scan Thorax untuk beberapa patologis tertentu seperti pada pendiagnosaan awal massa paru, klinis infeksi paru yang menyebabkan Chronic Pulmo Obstruction Disease (COPD), nodul paru, dan tuberculosis. Berdasarkan uraian tersebut, peneliti tertarik untuk mengkaji variasi penggunaan filter smooth dan filter $Y$-sharp yang bertujuan untuk mengetahui perbedaan citra anatomi dalam penggunaan kedua jenis filter tersebut dan mengetahui penggunaan filter yang dapat menghasilkan citra anatomi yang lebih baik.

\section{Metode}

Jenis penelitian yang dilakukan adalah penelitian pre-experimental design dengan metode staticgroup comparison sebagaimana yang terlihat dalam desain penelitian sebagai berikut:

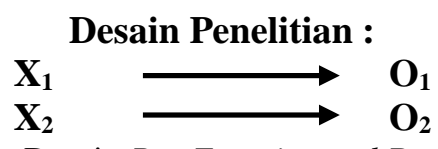

Gambar 1. Desain Pre-Experimental Design Metode Static-Group Comparison (Campbell, 1963)

Keterangan Gambar :

$\mathrm{X}_{1}$ : Filter Smooth

$\mathrm{X}_{2}$ : Filter $Y$-Sharp

$\mathrm{O}_{1}$ : Hasil citra anatomi dengan menggunakan filter Smooth

$\mathrm{O}_{2}$ : Hasil citra anatomi dengan meggunakan filter $Y$-Sharp

Variabel bebas dalam penelitian ini adalah ini adalah filter Smooth dan filter Y-Sharp sedang variabel terikatnya adalah citra anatomi $C T$ Scan Thorax yang meliputi kejelasan hilus paru, parenkim paru, dan batas pleura dengan mediastinum. Sampel dalam penelitian ini sebanyak 10 pasien yang dilakukan di RSUP Dr. Sardjito Yogyakarta dalam rentang waktu Maret - Mei 2018. Data penelitian ini diambil dari raw data pasien yang dilakukan pemeriksaan CT Scan Thorax dengan pengaturan range scan dari batas Batas atas apex paru dan batas bawah diafragma, faktor eksposi sebesar $120 \mathrm{kV} / 486 \mathrm{~mA}$, FOV $350 \mathrm{~mm}$, filter smooth dan Y-sharp, image matrix $512 \times 512$, slice thickness $1 \mathrm{~mm}$, increment $0.5 \mathrm{~mm}$, window width $1600 \mathrm{HU}$, dan window level -600 HU.

Data yang didapat berupa citra anatomi $C T$ Scan Thorax yang meliputi kejelasan hilus paru, parenkim paru, batas pleura dengan dinding thorax, dan fisura paru yang akan dinilai oleh dokter radiolog pada form check list dengan skala ordinal dan koefisien Cohen's Kappa sebesar 0,845. Data yang sudah dilakukan penilaian kemudian dianalisis dengan menggunakan uji statistik non parametrik Wilcoxon.

\section{Hasil dan Pembahasan}

Berdasarkan hasil penelitian di Instalasi Radiologi RSUP DR. Sardjito Yogyakarta didapatkan citra $C T$ Scan Thorax menggunakan variasi filter Smooth dan filter Y-Sharp pada Windowing Lung dengan karakteristik sampel berdasarkan jenis kelamin dalam penelitian ini adalah sebagai berikut: 
Tabel 1. Karakteristik sampel berdasarkan jenis

\begin{tabular}{cccc}
\multicolumn{3}{c}{ kelamin } \\
\hline No & $\begin{array}{c}\text { Jenis } \\
\text { Kelamin }\end{array}$ & Frekuensi & Persentase \\
& Laki-laki & 7 orang & $70 \%$ \\
2 & Perempuan & 3 orang & $30 \%$ \\
\hline & Total & 10 orang & $100 \%$ \\
\hline
\end{tabular}

Tabel 1 menjelaskan bahwa jenis kelamin lakilaki merupakan sampel terbanyak dalam penelitian ini dengan persentase $70 \%$ berjumlah 7 orang dari total 10 sampel.

Karakteristik sampel berdasarkan usia dalam penelitian ini adalah sebagai berikut:

Tabel 2. Karakteristik sampel berdasarkan usia

\begin{tabular}{cccc}
\hline No & Usia & Frekuensi & Persentase \\
\hline 1 & $31-40$ tahun & 2 orang & $20 \%$ \\
2 & $41-50$ tahun & 2 orang & $20 \%$ \\
3 & $51-60$ tahun & 2 orang & $20 \%$ \\
4 & 61-70 tahun & 4 orang & $40 \%$ \\
\hline & Total & 10 orang & $100 \%$ \\
\hline
\end{tabular}

Tabel 2 menjelaskan bahwa usia terbanyak pada rentang usia 61-70 tahun dengan persentase $40 \%$ sebanyak 4 orang dari total 10 sampel. Sedang rentang usia yang lain mempunyai jumlah seimbang dengan persentasi tiap usia pada $20 \%$.

Karakteristik sampel berdasarkan berat badan dalam penelitian ini adalah sebagai berikut :

Tabel 3. Karakteristik sampel berdasarkan berat badan

\begin{tabular}{cccc}
\hline No & $\begin{array}{c}\text { Berat } \\
\text { Badan }\end{array}$ & Frekuensi & Persentase \\
\hline 1 & $45-50 \mathrm{~kg}$ & 5 orang & $50 \%$ \\
2 & $51-55 \mathrm{~kg}$ & 2 orang & $20 \%$ \\
3 & $56-60 \mathrm{~kg}$ & 3 orang & $30 \%$ \\
\hline \multicolumn{2}{l}{ Total } & 10 orang & $100 \%$ \\
\hline
\end{tabular}

Tabel 3 menjelaskan bahwa berat badan sampel terbanyak pada rentang berat $45-50 \mathrm{~kg}$ dengan persentase $50 \%$ sebanyak 5 orang dari total 10 sampel. Sedang sampel terendah pada rentang berat adan 51-55 kg dengan persentase $20 \%$ sebanyak 2 orang.

Hasil citra CT Scan Thorax yang direkonstruksi menggunakan filter Smooth dapat dilihat dalam gambar berikut ini :
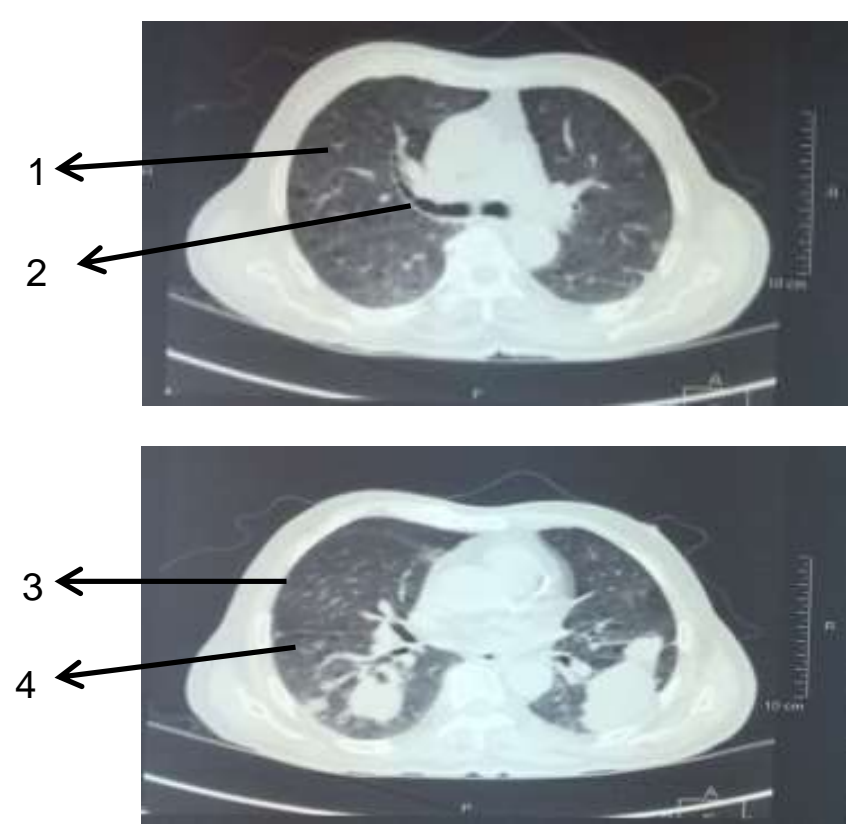

Gambar 1. Hasil Citra CT Scan Thorax Menggunakan Filter Smooth

Keterangan Gambar :
1. Parenkim
3. Batas Pleura dengan
Paru dinding Thorax
2. Hilus Paru
4. Fisura Paru

Hasil citra CT Scan Thorax yang direkonstruksi menggunakan filter $Y$-sharp dapat dilihat dalam gambar berikut ini :
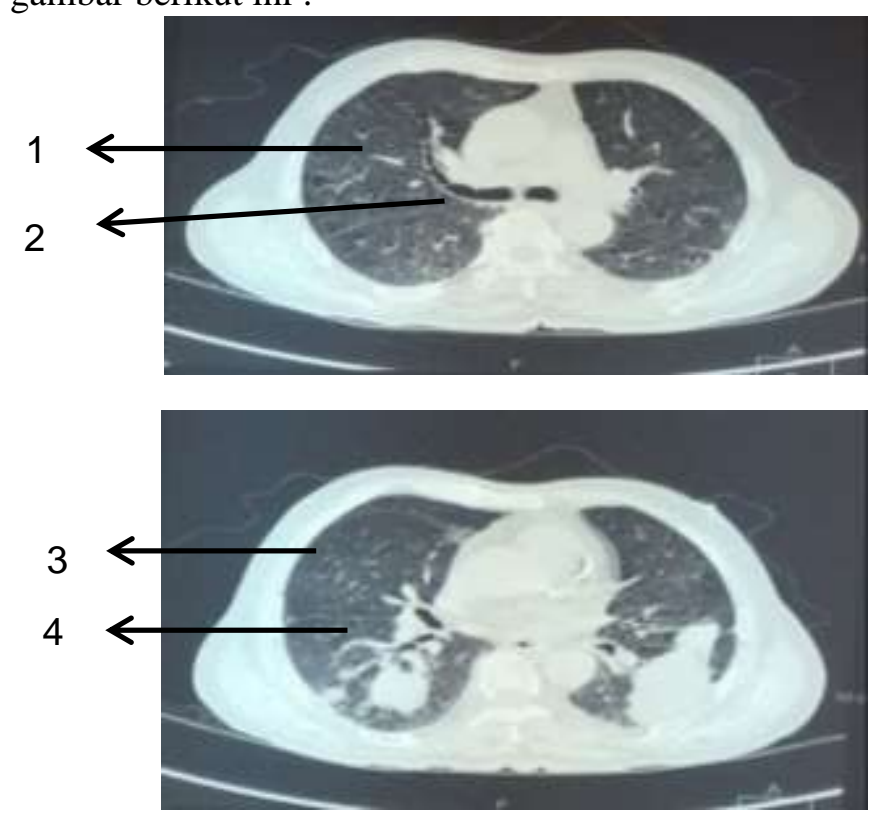
Gambar 2. Hasil Citra CT Scan Thorax Menggunakan Filter Y-Sharp Keterangan Gambar :

1. Parenkim Paru

3. Batas Pleura deng dinding Thorax

2. Hilus Paru

4. Fisura Paru

Penilaian uji beda untuk keseluruhan kriteria anatomi dapat dilihat dari tabel 4 sebagai berikut :

Tabel 4. Hasil Uji Beda Keseluruhan Kriteria Anatomi CT Scan Thorax Menggunakan Filter Smooth Dan Filter Y-Sharp

\begin{tabular}{cc}
\hline Filter & p-value \\
\hline $\begin{array}{c}\text { Variasi filter Smooth dan } \\
\text { filter } Y \text {-Sharp }\end{array}$ & 0,005 \\
\hline
\end{tabular}

Berdasarkan uji beda pada tabel 4 di atas menunjukkan ada perbedaan citra anatomi CT Scan Thorax antara penggunaan filter Smooth dengan filter $Y$-Sharp yang ditunjukkan dengan $p$-value 0,005 .

Sedang penilaian uji beda tiap kriteria anatomi dapat dilihat dari tabel 5 sebagai berikut :

Tabel 5. Hasil Uji Beda Tiap Kriteria Anatomi CT Scan Thorax Menggunakan Filter Smooth Dan Filter Y-Sharp

\begin{tabular}{lc}
\hline \multicolumn{1}{c}{ Kriteria Anatomi } & $\boldsymbol{p}$-value \\
\hline Hilus Paru & 0,020 \\
Parenkim Paru & 0,005 \\
Batas Pleura dengan dinding & 0,014 \\
Thorax & 0,025 \\
Fisura Paru & \\
\hline
\end{tabular}

Berdasarkan uji beda pada tabel 5 di atas menunjukkan ada perbedaan citra tiap kriteria anatomi CT Scan Thorax antara penggunaan filter Smooth dengan filter $Y$-Sharp yang ditunjukkan dengan $p$-value krtiteria anatomi hilus sebesar 0,020; pada parenkim paru sebesar 0,005; pada batas pleura dengan dinding thorax sebesar 0,014 ; dan pada fisura paru sebesar 0,025 .

Untuk mengetahui filter mana diantara Smooth dan $Y$-sharp yang dapat menghasilkan citra yang lebih optimal, maka dilakukan uji mean rank. Berdasarkan uji wilcoxon didapatkan mean rank untuk keseluruhan kriteria anatomi sebagai berikut :

Tabel 6. Hasil Mean Rank Keseluruhan Kriteria Anatomi CT Scan Thorax Menggunakan Filter Smooth Dan Filter $Y$-Sharp

\begin{tabular}{cc}
\hline Filter & Mean Rank \\
\hline Smooth & 0,00 \\
Y-Sharp & 5,50 \\
\hline
\end{tabular}

Berdasarkan tabel 6 didapatkan hasil mean rank untuk filter Y-Sharp sebesar 5.50 sedangkan filter an Smooth sebesar 0,00 sehingga dapat dinyatakan bahwa filter $Y$-Sharp lebih baik dalam menampilkan citra anatomi CT Scan Thorax.

Pada proses rekonstruksi citra terdapat kendala yang mengganggu berupa streak artefak. Gangguan ini bisa diminimalisasi dengan adanya filter. Filter pada dasarnya adalah perhitungan matematis komputer rumit yang digunakan untuk menentukan nilai atenuasi tiap pixel raw data hasil pencitraan $C T$ Scan yang berfungsi untuk merepresentasikan sebuah pencitraan obyek (Geyer et al, 2015). Proses dalam filter sering disebut dengan convolution. Proses convolution filter dapat merekonstruksi pixel-pixel yang berdekatan dalam sebuah input raw data agar yang menghasilkan perbedaan pada output raw data dengan menggunakan perhitungan matematis komputer yang rumit (Romans, 2011). Rekonstruksi pixel-pixel ini berkaitan dengan spatial frequency filtering (operasi komputer yang mengatur tingkat kecerahan/brightness dari sebuah citra). Spatial frequency filtering ini terdiri dari 2 jenis yaitu High Spatial Frequency (input raw data citra dengan pixel yang kecil yang memuat informasi frekuensi yang banyak) dan Low Spatial Frequency (input raw data citra dengan pixel yang besar yang memuat informasi frekuensi yang sedikit). Pada kedua jenis spatial frequency filtering inilah perbedaan proses filter jenis smooth dan sharp terjadi. Untuk mendapatkan citra dengan resolusi spasial dan detail lebih baik, convolution filter menekan low spatial frequency sehingga didapatkan perbedaan yang menonjol diantara pixel-pixel output raw data. Proses ini disebut dengan High Pass Filtering (Seeram, 2016). Namun proses ini berdampak dengan turunnya resolusi kontras dan bertambahnya noise citra (Romans, 2011). Sedangkan untuk mendapatkan citra yang lebih halus dan noise citra yang sedikit, convolution filter menekan high spatial frequency sehingga mereduksi perbedaan yang menonjol diantara pixelpixel output raw data. Proses ini disebut dengan Low Pass Filtering (Seeram, 2016). Namun proses ini berdampak dengan turunnya resolusi spasial.

Berdasarkan hasil penelitian ini, peneliti berpendapat bahwa pemilihan jenis filter yang berbeda menghasilkan citra $C T$ scan yang berbeda pula yang berimbas pada kejelasan citra dalam menampakkan informasi sehingga mempengaruhi hasil penilaian responden yang telah dianalisa berdasarkan hasil uji statistik. Hal tersebut sejalan dengan penelitian sebelumnya yang dilakukan oleh 
Zwirewich (1989) dalam jurnalnya yang menyatakan bahwa terdapat perbedaan tujuan antara penggunaan filter jenis smooth dan jenis sharp. Penggunaan filter jenis smooth disarankan pada pemeriksaan dengan tujuan mencari metastase/penyebaran keganasannya seperti metastase ke hepar dan kelenjar adrenal. Sedangkan penggunaan filter jenis sharp disarankan pada pemeriksaan CT Scan Thorax di area paru seperti pelacakan nodul solid paru, pelacakan massa paru, bronchiectasis, asbestos pleural disease karena dapat menampakkan secara detail dari bagian paru seperti parenkim, fisura dan hilus pada windowing lung tanpa mengurangi kualitas dari citra keseluruhan paru pada windowing mediastinum.

Hasil penelitian ini juga menyatakan bahwa filter $Y$-sharp menghasilkan citra yang lebih optimal dibanding filter smooth. Zwirewich (1989) dalam jurnalnya menyarankan penggunaan filter jenis sharp pada pemeriksaan CT Scan Thorax karena dapat meningkatkan resolusi spasial sebagai salah satu cara dalam meningkatkan kualitas citra. Peningkatan resolusi spasial berakibat pada meningkatnya detail terkecil suatu citra sehingga pendiagnosaan penyakit lebih akurat. Menurut Seeram (2016) filter sharp dapat menghasilkan citra dengan resolusi spasial yang lebih baik dikarenakan dalam proses rekonstruksinya terjadi high pass filtering yaitu ditekannya pixel-pixel besar yang memuat informasi atenuasi yang kecil sehingga berakibat besarnya perbedaan pixel-pixel yang berdekatan dalam output raw data. Meski mempunyai citra dengan resolusi spasial dan detail yang tinggi, tidak dipungkiri adanya dampak nosie citra yang tinggi pula.

\section{Simpulan}

Hasil penelitian ini dapat disimpulkan bahwa ada perbedaan citra anatomi $C T$ Scan Thorax antara penggunaan variasi filter smooth dan filter $Y$-sharp dengan p-value sebesar 0,005. Pemilihan filter $Y$ Sharp menghasilkan citra anatomi CT Scan Thorax yang lebih optimal daripada filter smooth.

\section{Daftar Pustaka}

Boedeker, Kirsten L. et al. 2004. Emphysema : Effect of Reconstruction Algorithm on CT Imaging Measures. Article Radiology in PubMed : www.researchgate.net (diakses tanggal 6 Februari 2018).

Campbell, Donald T. dan Julian C. Stanley. 1963. Experimental And Quasi Experimental
Design For Research. Houghton Mifflin Comapny : Boston.

Geyer, Lucas L., Joseph Schoepf, Felix G. Meinel, John W. Nance, Gorka Bastarrika, Jonathon A. Leipsic, Narinder S. Paul, Marco Rengo, Andrea Laghi, dan Carlo N. De Cecco. 2015. State of The Art : Iterative CT Reconstruction Technique. PubMed https://www.researchgate.net/publication/28 0390600 .

Henwood, Suzanne. 1999. Clinical CT Technique and Practice. Cambridge University Press : New York.

Romans, Lois E. 2011. Computed Tomography for Technologist, A Comprehensive Text. Wolter Kluwer Health/Lippincott Williams and Wilkins : Maryland dan Pensylvania.

Salito, Caterina, Jason C. Woods, dan Andrea Aliverti. 2011. Influence of CT Reconstruction Setting on Extremely Low Attenuation Values fo Spesifc Gas Volume Calculation in Severe Emphysema. Acad Radiol : National Public Access Author Manuscript.

Seeram, Euclid. 2016. Computed Tomography : Physical Principles, Clinical Applications, and Quality Control. Fourth Edition. W. B. Saunders Company. Philladelphia.

Zwirewich, Charles V., Blake Terriff, dan Nestor L. Muller. 1989. High Spatial Frequency (Bone) Algorithm Improves Quality of Standard CT of the Thorax. AJR Am J Roentgenol 153 : www.ajronline.org (diakses tanggal 6 Februari 2018). 